\title{
Cricoid pressure controversies
}

\section{Harpreet Kaur, Ravi Pareek, Harsh Kumar Harsh, Veena Shukla*, Nitin Tulsyan}

Department of Anaesthesiology and Critical care, SMS Medical College, Jaipur, Rajasthan, India

Received: 03 October 2020

Revised: 09 December 2020

Accepted: 14 December 2020

\section{*Correspondence:}

Dr. Veena Shukla,

E-mail: drshuklaveena@gmail.com

Copyright: ( ) the author(s), publisher and licensee Medip Academy. This is an open-access article distributed under the terms of the Creative Commons Attribution Non-Commercial License, which permits unrestricted non-commercial use, distribution, and reproduction in any medium, provided the original work is properly cited.

\begin{abstract}
Rapid sequence induction (RSI) is a common technique used in clinical anaesthesia to prevent pulmonary aspiration of gastric contents. Sellick introduced this in 1961. However, scientific validation to show the advantage of this technique in preventing aspiration is limited in literature. Numerous researches have shown that cricoid pressure (CP) application might have no benefit in preventing aspiration. Additionally this could lead to problems in securing the airway. Proper teaching and regular training sessions of this technique are mandatory in routine anaesthesia practice.
\end{abstract}

Keywords: Aspiration, Airway, Cricoid pressure, Rapid sequence induction

\section{INTRODUCTION}

Rapid sequence induction is a frequently used technique in anaesthesia practice in patients suspected of having full stomach and at risk of aspiration of gastric contents into the lungs. Walls et al in their longitudinal multicentre study on 8937 emergency patients undergoing tracheal intubations reported that in $69 \%$ patients $(6138$ out of 8937) RSI was method of choice. ${ }^{1}$ Sagarin et al in their prospective observational multicentre study concluded that in $78 \%$ of attempts of intubation, RSI resulted in 85$91 \%$ success rates. ${ }^{2}$ Additionally in another study by same author found that $81 \%$ of paediatric patients underwent RSI during emergency intubations and had high success rate of $78 \%$ and low complication rate $(1 \%){ }^{3}$ RSI is also most commonly used method during securing airway in intensive care unit (ICU) patients. ${ }^{4}$ Sequence of events during RSI includes prevention of hypoxia during induction and intubation, achieved by preoxygenation with $100 \%$ oxygen for 3-5 minutes prior to induction of anaesthesia. Objective of minimizing lag time between induction and intubation is attained by use of fast onset induction agent and neuromuscular blocker. Then cricoid pressure $(\mathrm{CP})$ is applied to prevent pulmonary aspiration of gastric contents. Alongside, intermittent positive pressure ventilation is avoided. Cricoid pressure application is continued until endotracheal tube is secured and its cuff inflated. ${ }^{5}$

\section{METHODS}

A lot of literatures highlighting potential pros and cons of using cricoid pressure during induction. We tried to compare latest studies in this field. This article tries to review various researches related to cricoid pressure use in anaesthesia. Extensive search was conducted through Medline, Pubmed, and Google Scholar using key words Rapid sequence induction, Cricoid pressure, Aspiration, Airway and Sellick's manoeuvre. Relevant studies were selected. This narrative review touches various aspects of use of cricoid pressure in anaesthesia.

\section{HISTORY}

Cricoid pressure application was used as early in 1774 (Monro) during resuscitation of drowning victims. ${ }^{6}$ 
Sellick in 1961 described a maneuver to prevent aspiration of regurgitated gastric contents during induction of anaesthesia which involved backward pressure on cricoid cartilage to temporary occlude upper esophagus. This would prevent gastric contents from reaching pharynx in case regurgitation occurs. ${ }^{7}$ Since then Sellick's maneuver became a part of emergency and anaesthesia practice during RSI.

However, Sellicks's original article was not specific regarding application of CP. Additionally. There is paucity of trials validating the application of $\mathrm{CP}$ in literature. Various authors like Butler et al and Fenton et al have evaluated available literature to check for favourable outcomes of using CP. Nevertheless, they found no evidence supporting use of Sellick's maneuver. ${ }^{8,9}$

Authors have even pointed out that frequency of morbidity due to aspiration is so common $(0.15 \%$ in adult patients), that a sample size of 25000 would be required in each group of patients if a randomized controlled trial (RCT) planned. ${ }^{10}$

\section{ANATOMICAL PERSPECTIVE}

Reviewing the anatomy, larynx is a cartilaginous organ covered by epiglottis at the base of tongue. Epiglottis prevents aspiration by covering the glottis during act of swallowing. ${ }^{11}$ Cricoid cartilage is a complete ring. Esophagus begins at the lower part of cricoid ring. CP supposedly compresses the upper esophagus against body of sixth cervical vertebra. ${ }^{12}$ Authors have challenged anatomical basis of CP. Schmalfuss et al in their study correlated CT and MRI images and showed that esophagus starts one centimetre below the lower end of cricoid cartilage. ${ }^{13}$

Rice et al demonstrated on MRI studies that post cricoid hypo pharynx and not esophagus lies distal to cricoid cartilage. ${ }^{14}$ Also Tsung et al observed on ultrasonography that esophagus lied lateral to trachea on application of cricoid pressure. ${ }^{15}$

Smith et al also echoed similar findings that in $49 \%$ of normal subjects, esophagus was aligned lateral to cricoid cartilage on CT scan images. In addition, it was found on MRI that lateral displacement of esophagus was in $52.6 \%$ patients without $\mathrm{CP}$ and $90.5 \%$ with CP. Airway compression resulting from $\mathrm{CP}$ was seen in $81 \%$ subjects. ${ }^{16}$

\section{HOW EFFECTIVE IS CP?}

The research conducted by Sellick had some major limitations. It was a non-randomized trial. During induction of anaesthesia, subjects were placed in slight head down and head turned position. Sellick reported $12 \%$ incidence of regurgitation after release of CP. In addition, details of the drugs and sequence of administration of induction agent as well as muscle relaxant are missing in the report. In addition, how much force was applied during $\mathrm{CP}$ is not described. ${ }^{17}$ Vanner and Pryle demonstrated lateral esophageal displacement on CT scans during application of CP. ${ }^{18}$

Rice et al also found that hypo pharynx present behind cricoid cartilage was compressed by CP. Due to lateral displacement of cricoid hypo pharynx unit or CP unit, the hypo pharynx is compressed between cricoid cartilage and longus colli muscle. Although upper esophagus is not compressed as proposed by Sellick, but hypo pharynx does compresses and helps in preventing regurgitation of stomach contents. ${ }^{14}$

Similar findings were echoed by Zeidan et al. ${ }^{19}$ Various other early reports are available on effectiveness of $\mathrm{CP}$ but they are mainly based on cadavers. ${ }^{20,21}$ Numerous case reports and studies point towards the unreliability and possibility of aspiration despite use of $\mathrm{CP}{ }^{22}$ Glaring among these is a prospective study on 297 critical patients in which 12 showed signs of pulmonary aspiration pneumonitis in spite of using $\mathrm{CP}$ while intubation in 9 of them. ${ }^{4}$

In addition, out of 5000 obstetrical patients under general anaesthesia, 11 patients died of regurgitation despite using CP in nine out of $11 .{ }^{9}$ However, other authors have proposed that these incidents could have been due to improper technique, administration by untrained personnel, early release, aspiration before induction or after extubation. ${ }^{23-25}$

Perioperative aspiration in routine settings is estimated to be $0.014 \%-0.1 \%$ in adults. ${ }^{26}$ However, this incidence escalates much higher in situations of emergency surgery and intubations especially with repeated attempts of intubation as well as in patients having American society of anaesthesiologists (ASA) status 3 and 4.4. ${ }^{27}$

A survey of 2833 emergency intubations showed a $1.9 \%$ incidence of aspiration which hiked to $22 \%$ with three or more attempts of intubation. Moreover, mortality from perioperative aspiration has been reported to be as high as $4.6 \% .^{28}$ Authors have also reported aspiration of gastric contents as single most common anaesthesia related cause of death, accounting for $50 \%$ of mortality and prolong morbidity. ${ }^{29}$ There is lack of RCTs comparing incidence of aspiration with and without CP.

\section{MAGNITUDE OF CRICOID PRESSURE}

Sellick used terms 'moderate' and 'firm' pressure in his study. ${ }^{7}$ According to Wraight et al, assuming intragastric pressure to be $59 \mathrm{~mm} \mathrm{Hg}$ in $50 \%$ patients, recommended $\mathrm{CP}$ force was 44 Newton $(\mathrm{N}) .{ }^{29}$ Another study revealed that $\mathrm{CP}$ force of $20 \mathrm{~N}$ was enough to prevent regurgitation at intragastric pressure of $25 \mathrm{~mm} \mathrm{Hg}$ and $30 \mathrm{~N}$ force prevented regurgitation at $40 \mathrm{~mm} \mathrm{Hg} .{ }^{30}$ 
Studies have shown that under anaesthesia intragastric pressure is less than $15 \mathrm{~mm} \mathrm{Hg} .{ }^{31}$ Even pregnant females undergoing emergency caesarean sections have pressures less than $25 \mathrm{~mm} \mathrm{Hg}^{32}$ On basis of these researches $20 \mathrm{~N}$ force has been found to be adequate. It is recommended that $10 \mathrm{~N}$ force should be applied when patient is awake which is to be increased to $30 \mathrm{~N}$ on loss of consciousness. ${ }^{23}$

\section{AIRWAY IMPLICATIONS OF CP}

\section{Airway obstruction}

Airway patency compromise difficult mask ventilation, endotracheal tube insertion, rail roading the tube over bougie, problems in visualisation during fibre optic scopy have been reported due to excess cricoid force application..$^{33,34}$

Inversely, a study conducted on 700 elective surgical patients did not increase rate of failed intubations. ${ }^{34}$ Airway obstruction depends on the force and technique of application. ${ }^{35}$ One study has shown that $44 \mathrm{~N}$ force causes airway obstruction in $35 \%$ patients while only in $2 \%$ cases in case force applied is $30 \mathrm{~N} .{ }^{34}$ In case of paediatric patients, $10.5 \mathrm{~N}$ is sufficient to cause airway obstruction. It is $5 \mathrm{~N}$ for infants and $15-25 \mathrm{~N}$ in teenagers. ${ }^{36}$ In fact; German society of anaesthesia and intensive care medicine has recommended not using cricoid pressure in children. $^{37}$

\section{Laryngeal view and $C P$}

Various studies have evaluated the laryngoscopic view during $\mathrm{CP}$ application. Though $\mathrm{CP}$ improves the laryngoscopic view, it may worsen it in $14-45 \%$ of cases. $^{38} \mathrm{~A}$ recent study also concluded that tracheal intubation is hindered using $\mathrm{CP}^{39}$

Use of neck support by using a neck pillow or by bimanual CP has shown to improve laryngoscopic view during $\mathrm{CP}$. In this technique, one hand performs the $\mathrm{CP}$ and other is placed below the neck for support. ${ }^{40}$

\section{Supraglottic airway devices and CP}

In case of LMA insertion, CP is applied before insertion, it may lead to malpositioning of LMA and problem in ventilation. ${ }^{41} \mathrm{CP}$ application after LMA insertion also impedes ventilation. ${ }^{42}$

In case of fiberoptic intubation through LMA, CP application before LMA insertion leads to successful intubation only in $15 \%$ cases, which is otherwise $89-95 \%$ without $\mathrm{CP}$. If $\mathrm{CP}$ is applied subsequent to LMA insertion, successful fiberoptic intubation is seen in $60 \%$ cases and intubation time is prolonged. ${ }^{41,43}$ I gel placement may also be difficult along with $\mathrm{CP}$ application. ${ }^{44}$
Seeing complexity of the situation, researches have recommended that in patients with difficult airway who is at high risk of aspiration, awake intubation is advisable. ${ }^{43,45}$

\section{NASOGASTRIC TUBE AND CP}

Sellick recommended suctioning and removal of Ryles tube before $\mathrm{CP}$ application. He hypothesised that presence of nasogastric tube might lower the tone of upper and lower oesophagus sphincters. ${ }^{7}$ However, studies have confirmed that $\mathrm{CP}$ is effective even in presence of nasogastric tube. ${ }^{21}$

Salem et al have proposed that nasogastric tube should be connected to working suction while applying CP during induction to prevent rise in intragastric pressure. ${ }^{46}$

\section{COMPLICATIONS}

Nausea and vomiting in awake patients, airway obstruction, oesophageal rupture, cricoid cartilage fracture, worsening of cervical spine injuries are other reported complications of $\mathrm{CP} .{ }^{33,35,47,48}$

\section{TEACHING THE PROPER TECHNIQUE}

Researchers have reported that large number of operators (47-63\%) applies CP in an improper way. ${ }^{24,49}$ Brisson and Brisson in their study noticed a large variability in technique of $\mathrm{CP}$ application, which can lead to wrong application of cricoid pressure. They recommended the 'three finger technique' as advised by Sellick. ${ }^{49}$ Armstrong et al have explained that CP should be started as soon as patient loses consciousness and should be continued till endotracheal tube is in place with inflated cuff and EtCO $\neg 2$ curve is observed. ${ }^{50}$

Kopka et al and Flucker et al have recommended that application of correct amount of force while CP application should be practiced regularly on monthly basis using a $50 \mathrm{ml}$ syringe plunger. $50 \mathrm{ml}$ syringe filled with $50 \mathrm{ml}$ air. After capping and placing upright plunger is pressed by $12 \mathrm{ml}$ for $20 \mathrm{~N}$ force and $17 \mathrm{ml}$ for $30 \mathrm{~N}$ force..$^{51,52}$

In addition to three-finger technique (single-handed) which is used popularly, double-handed (bimanual) technique may also be used especially for trauma and obstetric patients. Advantages include prevention of head flexion, stabilization of cervical spine and better visualization of larynx. ${ }^{40,48}$ In recent guidelines, use of $\mathrm{CP}$ during cardiac arrest is not recommended. ${ }^{33,35,53-55}$

Many devices has been described to help in cricoid compression, these include cricoid yoke, cricoid pressure measuring device using wedge and pin combination, force sensitive resistors to estimate cricoid force. Use of floor weighing machine has been used also with success. Operator stands on weighing scale then $\mathrm{CP}$ is applied 
until weight reading on weighing machine reduces by 2.5 to $3.5 \mathrm{~kg}$ less than original weight of operator. It means that $25-35 \mathrm{~N}$ force has been applied $(1 \mathrm{~kg}: 9.8 \mathrm{~N})$. Use of simulators has been demonstrated for training and teaching application of CP. ${ }^{56-59}$

\section{CONCLUSION}

Some anaesthesiologists have proposed to abandon the use of cricoid pressure. However, the findings that aspiration largest cause of anaesthetic related deaths and morbidity has lead clinicians to rethink regarding this issue. Although pulmonary aspiration has occurred despite use of $\mathrm{CP}$ as described in various studies it is suggested that CP may not have been applied properly or may have been released prematurely etc.

Important is to assess the risks and benefits of using $\mathrm{CP}$ on case to case basis, more randomised controlled trials are awaited in this subject. In addition, stress on proper and periodic training of anaesthesiologists in this very commonly used controversial and still important technique is the need of hour.

Funding: No funding sources

Conflict of interest: None declared

Ethical approval: Not required

\section{REFERENCES}

1. Walls RM, Brown CA, Bair AE, Pallin DJ. Emergency airway management: a multi-centre report of 8937 emergency department intubations. J Emerg Med. 2011;41:347-54.

2. Sagarin MJ, Barton ED, Chng YM, Walls RM, National Emergency Airway Registry Investigators. Airway management by US and Canadian emergency medicine residents: a multicenter analysis of more than 6,000 endotracheal intubation attempts. Ann Emerg Med. 2005;46:328-36.

3. Sagarin MJ, Chiang V, Sakles JC, Barton ED, Wolfe RE, Vissers RJ, et al. Rapid sequence intubation for pediatric emergency airway management. Pediatr Emerg Care. 2002;18:417-23.

4. Schwartz DE, Matthay MA, Cohen NH. Death and other complications of emergency airway management in critically ill adults. A prospective investigation of 297 tracheal intubations. Anesthesiology. 1995;82:367-76.

5. Stewart JC, Bhananker S, Ramaiah R. Rapidsequence intubation and cricoid pressure. Int J Crit Illn Inj Sci. 2014;4(1):42-9.

6. Salem MR, Sellick BA, Elam JO. The historical background of cricoid pressure in anesthesia and resuscitation. Anesth Analg. 1974;53:230-2.

7. Sellick BA. Cricoid pressure to control regurgitation of stomach contents during induction of anaesthesia. Lancet. 1961;2:404-6.
8. Butler J, Sen A. Best evidence topic report. Cricoid pressure in emergency rapid sequence induction. Emerg Med J. 2005;22:815-6.

9. Fenton PM, Reynolds F. Life-saving or ineffective? An observational study of the use of cricoid pressure and maternal outcome in an African setting. Int $\mathrm{J}$ Obstet Anesth. 2009;18:106-10.

10. Lerman J. On cricoid pressure: "May the force be with you". Anesth Analg. 2009;109:1363-6.

11. Murray MJ, Coursin DB, Pearl RG, Prough DS, editors. Critical Care Medicine: Perioperative Management. Philadelphia: Lippincott-Raven Publishers; 1997. Management of the airway and endotracheal intubation.

12. Landsman I. Cricoid pressure: Indications and complications. Paediatr Anaesth. 2004;14:43-7.

13. Schmalfuss IM, Mancuso AA, Tart RP. Postcricoid region and cervical esophagus: normal appearance at CT and MR imaging. Radiology. 2000;214:237-46.

14. Rice MJ, Mancuso AA, Gibbs C, Morey TE, Gravenstein N, Deitte LA. Cricoid pressure results in compression of the postcricoid hypopharynx: The esophageal position is irrelevant. Anesth Analg. 2009; $109: 1546-52$.

15. Tsung JW, Fenster D, Kessler DO, Novik J. Dynamic anatomic relationship of the esophagus and trachea on sonography: implications for endotracheal tube confirmation in children. $\mathbf{J}$ Ultrasound Med. 2012;31:1365-70.

16. Smith KJ, Dobranowski J, Yip G, Dauphin A, Choi PT. Cricoid pressure displaces the esophagus: an observational study using magnetic resonance imaging. Anesthesiology. 2003;99:60-4.

17. Bhatia N, Bhagat H, Sen I. Cricoid pressure: where do we stand? J Anaesthesiol Clin Pharmacol. 2014;30:3-6.

18. Vanner RG, Pryle BJ. Nasogastric tubes and cricoid pressure. Anaesthesia. 1993;48:1112-3.

19. Zeidan AM, Salem MR, Mazoit JX, Abdullah MA, Ghattas T, Crystal GJ. The effectiveness of cricoid pressure for occluding the esophageal entrance in anesthetized and paralyzed patients: an experimental and observational glidescope study. Anesth Analg. 2014;118:580-6.

20. Fanning GL. The efficacy of cricoid pressure in preventing regurgitation of gastric contents. Anesthesiology. 1970; 32:553-5.

21. Salem MR, Joseph NJ, Heyman HJ, Belani B, Paulissian R, Ferrara TP. Cricoid compression is effective in obliterating the esophageal lumen in the presence of a nasogastric-tube. Anesthesiology. 1985;63:443-6.

22. Cook TM, Godfrey I, Rockett M, Vanner RG. Cricoid pressure: Which hand? Anaesthesia. 2000;55:648-53.

23. Vanner RG, Asai T. Safe use of cricoid pressure. Anaesthesia. 1999;54:1-3.

24. Nafiu OO, Bradin S, Tremper KK. Knowledge, attitude, and practice regarding cricoid pressure of 
ED personnel at a large US teaching hospital. J Emerg Nurs. 2009;35:11-5.

25. Ovassapian A, Salem MR. Sellick's maneuver: To do or not do. Anesth Analg. 2009;109:1360-2.

26. Ellis DY, Harris T, Zideman D. Cricoid pressure in emergency department rapid sequence tracheal intubations: a risk-benefit analysis. Ann Emerg Med. 2007;50:653-65.

27. Ufberg JW, Bushra JS, Karras DJ, Satz WA, Kueppers F. Aspiration of gastric contents: Association with prehospital intubation. Am J Emerg Med. 2005;23:379-82.

28. $\mathrm{Ng} \mathrm{A,} \mathrm{Smith} \mathrm{G.} \mathrm{Gastroesophageal} \mathrm{reflux} \mathrm{and}$ aspiration of gastric contents in anesthetic practice. Anesth Analg. 2001;93:494-513.

29. Wraight WJ, Chamney AR, Howells TH. The determination of an effective cricoid pressure. Anaesthesia. 1983;38:461-6.

30. Vanner RG, Pryle BJ. Regurgitation and oesophageal rupture with cricoid pressure: A cadaver study. Anaesthesia. 1992;47:732-5.

31. Haslam N, Syndercombe A, Zimmer CR, Edmondson L, Duggan JE. Intragastric pressure and its relevance to protective cricoid force. Anaesthesia. 2003;58:1012-5.

32. Roe RB. The effect of suxamethonium on intragastric pressure. Anaesthesia. 1962;17:179-81.

33. Turgeon AF, Nicole PC, Trépanier CA, Marcoux S, Lessard MR. Cricoid pressure does not increase the rate of failed intubation by direct laryngoscopy in adults. Anesthesiology. 2005;102:315-9.

34. McNelis U, Syndercombe A, Harper I, Duggan J. The effect of cricoid pressure on intubation facilitated by the gum elastic bougie. Anaesthesia. 2007;62:456-9.

35. Koufman JA, Fortson JK, Strong MS. Predictive factors of cricoid ring size in adults in relation to acquired subglottic stenosis. Otolaryngol Head Neck Surg. 1983;91:177-82.

36. Aoyama K, Takenaka I, Sata T, Shigematsu A. Cricoid pressure impedes positioning and ventilation through the laryngeal mask airway. Can J Anaesth. 1996;43:1035-40.

37. Weiss M, Gerber AC. Rapid sequence induction in children - It's not a matter of time! Paediatr Anaesth. 2008;18:97-9.

38. Vanner RG. Cricoid pressure. Int J Obstet Anesth. 2009; 18:103-5.

39. Crowley DS, Giesecke AH. Bimanual cricoid pressure. Anaesthesia. 1990;45:588-9.

40. Cook TM. Cricoid pressure: Are two hands better than one? Anaesthesia. 1996;51:365-8.

41. Strang TI. Does the laryngeal mask airway compromise cricoid pressure? Anaesthesia. 1992;47:829-31.

42. Asai T, Murao K, Shingu K. Cricoid pressure applied after placement of laryngeal mask impedes subsequent fibreoptic tracheal intubation through mask. Br J Anaesth. 2000;85:256-61.
43. Hashimoto Y, Asai T, Arai,T, Okuda Y. Effect of cricoid pressure on placement of the I-gel ${ }^{\mathrm{TM}}$ : A randomised study. Anaesthesia. 2014;69:878-82.

44. Apfelbaum JL, Hagberg CA, Caplan RA, Blitt CD, Connis RT, Nickinovich DG, et al. Practice guidelines for management of the difficult airway: an updated report by the American Society of Anesthesiologists Task Force on Management of the Difficult Airway. Anesthesiology. 2013;118:251-70.

45. Salem MR, Wronski CJ, Khorasani A, Crystal GJ. Which is the original and which is the modified rapid sequence induction and intubation? Let history be the judge! Anesth Analg. 2013;116:264-5.

46. Salem MR, Khorasani A, Saatee S, Crystal GJ, ElOrbany M. Gastric tubes and airway management in patients at risk of aspiration: History, current concepts, and proposal of an algorithm. Anesth Analg. 2014;118:569-79.

47. Heath KJ, Palmer M, Fletcher SJ. Fracture of the cricoid cartilage after Sellick's manoeuvre. Br J Anaesth. 1996;76:877-8.

48. Gabbott DA. The effect of single-handed cricoid pressure on neck movement after applying manual in-line stabilisation. Anaesthesia. 1997;52:586-8.

49. Brisson P, Brisson M. Variable application and misapplication of cricoid pressure. J Trauma. 2010;69:1182-4.

50. Armstrong B, Reid C, Heath P, Simpson H, Kitching J, Nicholas $J$, et al. Rapid sequence induction anaesthesia: A guide for nurses in the emergency department. Int Emerg Nurs. 2009;17:161-8.

51. Kopka A, Crawford J. Cricoid pressure: A simple, yet effective biofeedback trainer. Eur J Anaesthesiol. 2004;21:443-7.

52. Flucker CJ, Hart E, Weisz M, Griffiths R, Ruth M. The 50-millilitre syringe as an inexpensive training aid in the application of cricoid pressure. Eur $\mathrm{J}$ Anaesthesiol. 2000;17:443-7.

53. 53.Smith CE, Boyer D. Cricoid pressure decreases ease of tracheal intubation using fibreoptic laryngoscopy (WuScope System. Can J Anaesth 2002; 49:614-9 [Article] [PubMed]

54. Johnson RL, Cannon EK, Mantilla CB, Cook DA. Cricoid pressure training using simulation: A systematic review and meta-analysis. $\mathrm{Br} \mathrm{J}$ Anaesth. 2013;111:338-46.

55. Taylor RJ, Smurthwaite G, Mehmood I, Kitchen GB, Baker RD. A cricoid cartilage compression device for the accurate and reproducible application of cricoid pressure. Anaesthesia. 2015;70:18-25.

56. Lawes EG. Cricoid pressure with or without the “cricoid yoke". Br J Anaesth. 1986;58:1376-9.

57. Connor CW, Saffary R, Feliz E. Performance of the Sellick maneuver significantly improves when residents and trained nurses use a visually interactive guidance device in simulation. Physiol Meas. 2013;34:1645-56. 
58. Clayton TJ, Vanner RG. A novel method of measuring cricoid force. Anaesthesia. 2002;57:3269.

59. May P, Trethewy C. Practice makes perfect? Evaluation of cricoid pressure task training for use within the algorithm for rapid sequence induction in critical care. Emerg Med Australas. 2007;19:207-12.
Cite this article as: Kaur H, Pareek R, Harsh HK, Shukla V, Tulsyan N. Cricoid pressure controversies. Int J Community Med Public Health 2021;8:468-73. 